\title{
Research on Hydraulic System Optimization of Loader Based on GA-BP
}

\author{
Zhang Hua, Zhao Lei, Chen Hua \\ School of Electrical and Electronic Engineering, Chongqing Vocational and Technical University of Mechatronics, Bi \\ Shan 402760, China. \\ E-mail: zhanghua198716@126.com, zhaolei185@126.com,chenhua199019@126.com \\ Corresponding author: Zhao Lei; Corresponding e-mail: zhaolei185@126.com
}

\begin{abstract}
Aiming to study the working efficiency and stability of the loader, the hydraulic system of the loader is studied. Taking the ZL50 loader as the research carrier, the working conditions of the loader and the working principle of the hydraulic system are analysed at first. AEMSim software is used to simulate and analyse the hy-draulic system, and the necessity of using the algorithm to optimize the hydraulic system is put forward. Secondly, the mathematical model of key hydraulic system optimization is deduced, and genetic algorithm and neural net-work algorithm are used to optimize the analysis of the objective function, and the simulation results are compared and analysed again. The results show that the parameters optimized by GA and BP algorithm are better than the original parameters. Further analysis shows that the parameters optimized by GA algorithm are better than BP algorithm in smoothness.
\end{abstract}

Keywords: Loader; Hydraulic system; Simulation; Genetic Algorithm; Optimization analysis

\section{Introduction}

Loader as a kind of common construction machinery is widely used in engineering construction. The requirement of the reliability and safety of the loader is higher and higher. The hydraulic system of the loader is an important executive part of the loader. It is directly related to the reliability and service life of the loader. Loader has a high requirement for hydraulic system in its work. The hydraulic system requires accurate and reliable control of working pressure, speed and position to ensure the work to be carried out. But in the actual operation, the common problems of loader, such as weak operation, intermittent jitter, and hydraulic cylinder leakage and so on, have a direct impact on the progress of the project. At the same time, according to different operating conditions, the work load is different, which makes the hydraulic system more direct to the performance of the loader. Many scholars have also studied the working performance of loaders. For example, Wan Yiping [1] carried out the dynamic simulation and experimental study on the working device of the loader. The results show that the error between the measured hinge force and the simulation value is between $6.22 \%$ and $11.5 \%$. You Yong [2] studied the automatic shift control strategy of hydraulic mechanical automatic transmission (HMPRT) of loader based on dynamic programming. In this paper, the fuel consumption is reduced by $3.5 \%$ compared with the optimal power shift rule and the number of shifts is reduced by $33.3 \%$ compared with the optimal economic shift rule when the shift rule proposed by dynamic programming is adopted. The main purpose of this study is to avoid frequent gear shifts. Aiming at the lubrication problem of wheel loader. Liu Fuxin[3] realized the reasonable lubrication of wheel loader by upgrading the lubricating oil and adopting the centralized lubrication system, reduced the maintenance workload and obtained good economic benefits. A new type of fixed/variable displacement hydraulic system for loader was designed by Jian Z [4], and the working prin- ciple and energy consumption of the system were analysed. Park S H [5] developed the simulation program of the hydraulic circuit of wheel loader by modelling the main pump, main control valve (MCV), compensator, lever and accessories in the hydraulic circuit of wheel loader according to their specifications. The model is used to simulate various external conditions encountered in the actual working environment. In most of the loader research process, there is little optimization analysis of the hydraulic system algorithm. In view of this, this article proposes the preliminary AEMSim modelling and simulation analysis for the hydraulic system of the loader, and then establishes the optimization mathematical model for the key hydraulic system, and optimizes it by genetic algorithm and neural network algorithm. Then the parameters of the optimization results are modelled and simulated. Finally, the differences before and after optimization are analysed and compared, and the nearest optimization algorithm is obtained. At the same time, this method is used to explore the optimization simulation of the hydraulic system of the loader. It provides a set of research methods for similar research in the future.

\section{Research Framework of Inverted Edge and Design of Hydraulic System of Loader}

\subsection{Overall research framework}

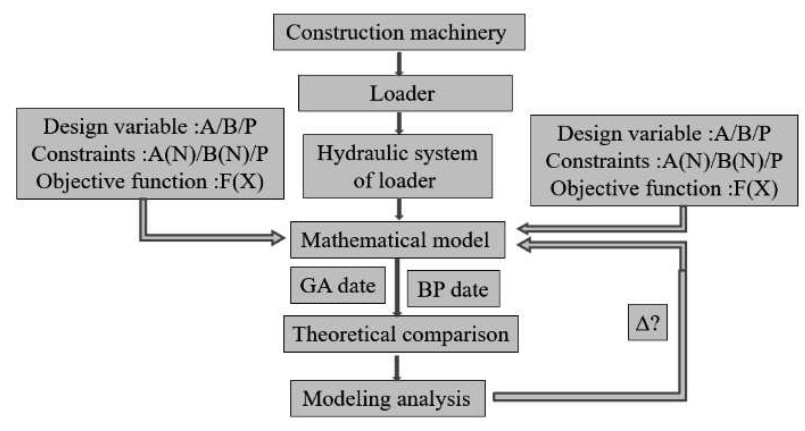

Fig. 1 Main research framework 
This method is mainly based on the hydraulic system of loader in construction machinery. ZL50 loader is selected as the research object, and the overall research ideas are formulated, as shown in Figure 1.

\subsection{Design of Hydraulic System for ZL50 Loader}

According to Figure 1, the hydraulic system of the ZL50 loader is analysed and the schematic diagram of the hydraulic system is designed. The ZL50 loader is a wheel loader. Its basic actions include inserting the bucket into the material, turning the bucket backwards, holding the load and raising it to a certain height, conveying the load to the designated place for dumping and returning to the loading place, and so on[6-9]. At present, all wheel loaders adopt hydraulic steering. Design the hydraulic system according to the functional requirements, as shown in figure 2 .

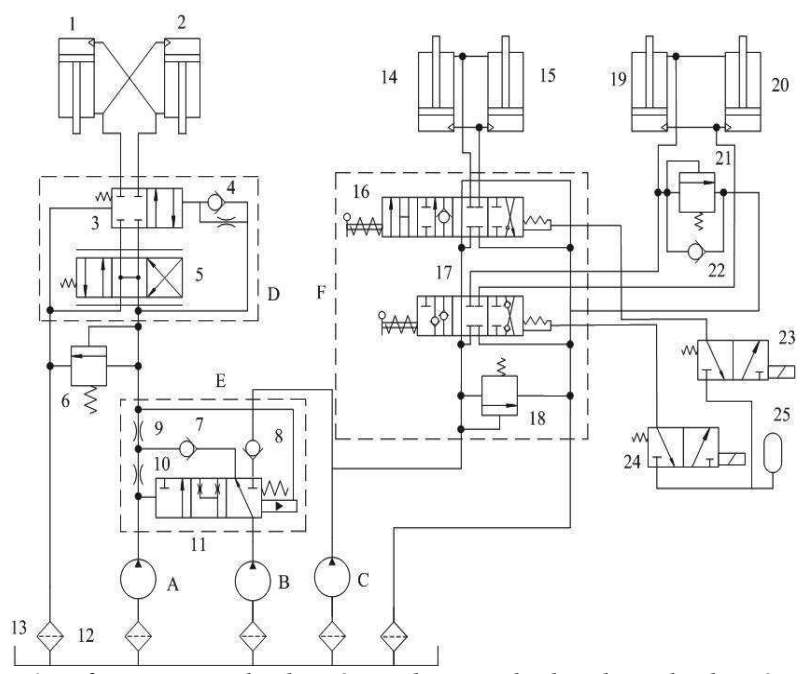

1.Left steering cylinder; 2. Right steer hydraulic cylinder; 3 . Two-position four-way directional valve; 4. One-way throttle valve; 5 . Three-position four-way directional valve; 6 . Overflow valve; 7, 8, 22. One-way valve; 9, 10. Throttle valve; 11 . Three-position three-way reversing valve; 12. Filt; 13. Mailbox; 14. Left boom hydraulic cylinder; 15. Right boom hydraulic cylinder; 16. Four-position six-way reversing valve; 17. Three-position six-way reversing valve; 18 . Overflow valve; 19. Left bucket hydraulic cylinder; 20. Right bucket hydraulic cylinder; 21. Overflow valve; 23, 24. Solenoid valve; 25. Gas storage tank; A. Main pump; B. Auxiliary pump; C. Steering pump; E. Flow control valve; F. Sequential single-action loop

Fig. 2 Hydraulic System Schematic Diagram of ZL50 Loader

As shown in figure. 2, this hydraulic system is compose of a hydraulic oil source circuit/working device circuit and a steering circuit. The hydraulic oil source circuit is composed of three quantitative hydraulic pumps and a flow control valve. The pump A is the main pump driving the working device, the pump $\mathrm{C}$ is the steering pump and the pump B is the auxiliary pump. The B pump can supply oil to both the working device and the steering circuit. When the engine speed is at the low speed-the designed speed-the highest speed, the main spool spring preload of the flow control valve $\mathrm{E}$ is driven by the pressure difference of the throttle holes 9 and 10 , so that the main spool is in the right, middle and left positions, respectively. Because the flow control valve $\mathrm{E}$ is adopted in the hydraulic oil source circuit, the flow rate of the steering system is not affected by the change of the engine speed, and the requirement of flexible and stable steering is ensured.

The working device circuit adopts the sequential single-action circuit $\mathrm{F}$, the bucket hydraulic cylinder is in the front and the boom hydraulic cylinder is in the rear, which constitutes the sequential interlock. The bucket hydraulic cylinder is controlled by a manual three-position six-way one-way valve 17 , and has three actions of up-turning, locking and down-turning, and a limited position mechanism is provided. When the bucket is finished tipping and unloading at elevation and the reversing valve 17 is operated to rotate the bucket to a certain position, the twoposition three-way solenoid valves 23 and 24 of the pneumatic system are operated to connect the air path, the compressed air enters the three-position six-way manual reversing valve 17 to push the bouncing positioning steel ball, and the valve core returns to the middle position under the spring force to automatically limit the bucket. The four-position six-way reversing valve 16 in this circuit is raised, lowered, and floated when the spool is in different positions.

The ZL50 hydraulic system uses a time-combined steering circuit. The main purpose of the invention is to connect the working circuit and the steering circuit with the auxiliary pump B through the flow control valve E, so as to obtain relatively perfect specific performance and meet the performance requirements of the working device at the same time.

\section{Simulation analysis}

\subsection{Establishment of AMESim Simulation Model}

Aiming at the above analysis of hydraulic system, the hydraulic system of ZL50 loader is simulated and modelled by using AMESim hydraulic simulation software and relevant parameters are set [10-12]. The AMESim model is shown in Figure 3, and the main parameters and settings are shown in table 1.

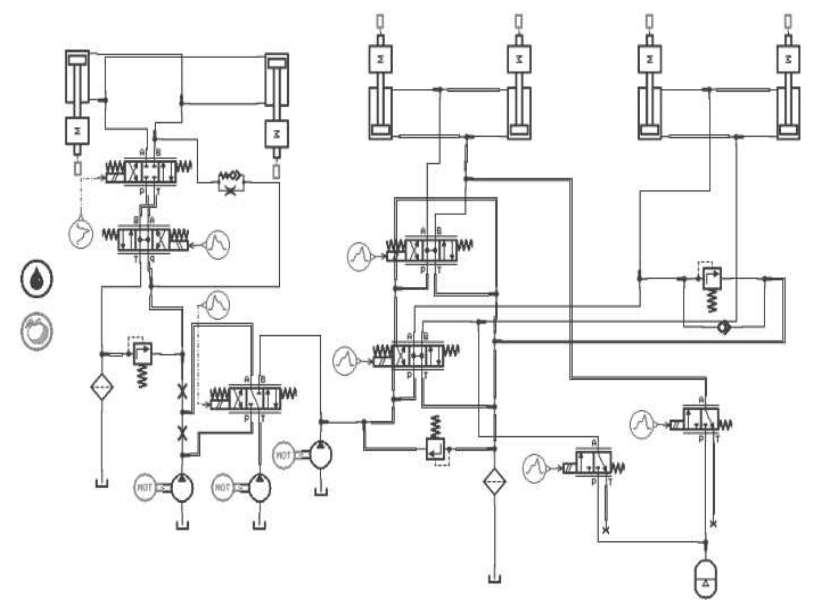

Fig. 3 AMESim Model of Hydraulic System of ZL50 Loader 
Tab. 1 Main Parameters and Settings of Hydraulic System of ZL50 Loader

\begin{tabular}{|c|c|c|c|}
\hline Component & Control quantity & Value & Unit \\
\hline Motor & Revolutions & 1500 & $\mathrm{rev} / \mathrm{min}$ \\
\hline \multirow{2}{*}{ Pump A } & Displacement & 100 & $\mathrm{cc} / \mathrm{rev}$ \\
\cline { 2 - 4 } & Revolutions & 1000 & $\mathrm{cc} / \mathrm{min}$ \\
\hline \multirow{2}{*}{ Pump B } & Displacement & 100 & $\mathrm{rev} / \mathrm{min}$ \\
\cline { 2 - 4 } & Revolutions & 1000 & $\mathrm{cc} / \mathrm{rev}$ \\
\hline \multirow{2}{*}{ Pump C } & Displacement & 100 & $\mathrm{rev} / \mathrm{min}$ \\
\cline { 2 - 4 } & Revolutions & 1000 & $\mathrm{~Hz}$ \\
\hline Reversing valve & Frequency & 80 & $\mathrm{~mm}$ \\
\hline Overflow valve & Opening pressure & 150 & $\mathrm{~mm}$ \\
\hline \multirow{2}{*}{ Hydraulic cylinder } & Piston diameter & 12 & $\mathrm{Kg}$ \\
\cline { 2 - 4 } & Rod diameter & 1000 & $\mathrm{~m}$ \\
\cline { 2 - 4 }
\end{tabular}

\subsection{Analysis of simulation results}

As shown in that model and parameter setting table 1 of figure 1, the simulation result of the hydraulic system of the ZL50 loader are analysed. The output displacement curves of the hydraulic cylinders 1, 2, 14, 15, 19, 20 are shown in figure 4 . The output pressure curves of the hydraulic cylinders $1,2,14,15,19,20$ are shown in figure 5 . The output flow curves of the hydraulic cylinders $1,2,14$, $15,19,20$ are shown in figure 6 . The piston speed curves of the hydraulic cylinders $1,2,14,15,19,20$ are shown in figure 7 .

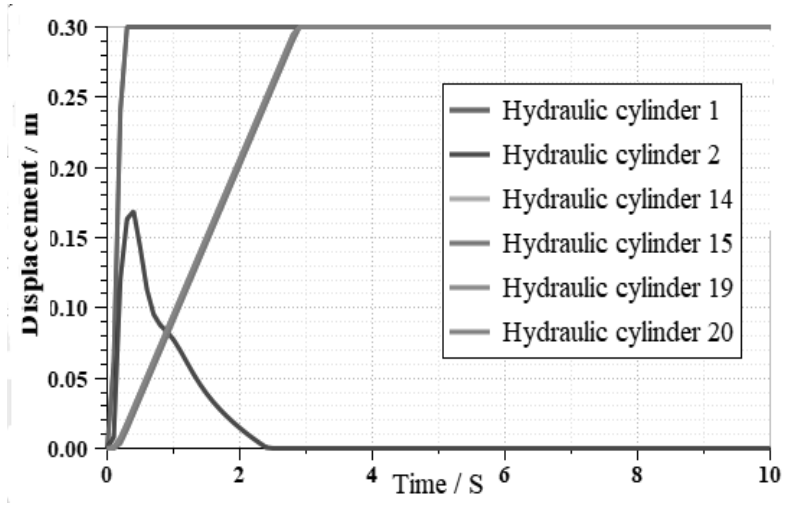

Fig. 4 Output displacement curve of hydraulic cylinders $1,2,14,15,19,20$

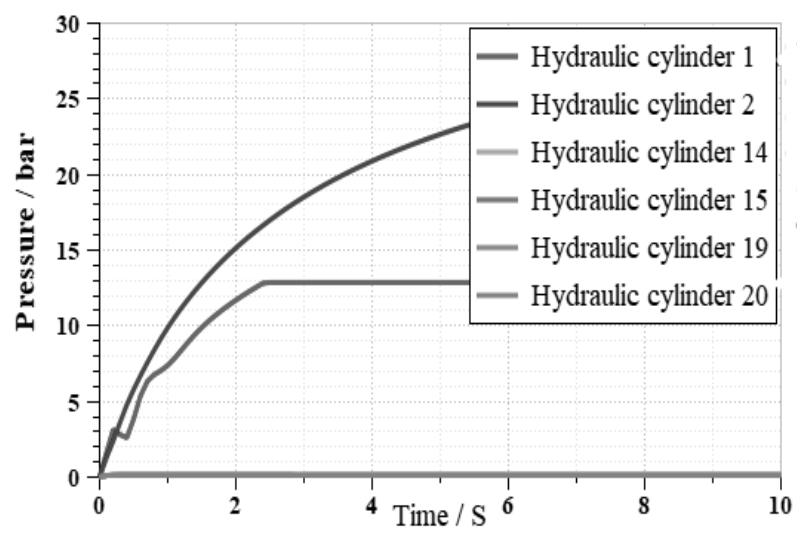

Fig. 5 Output pressure curve of hydraulic cylinders 1, 2, $14,15,19,20$

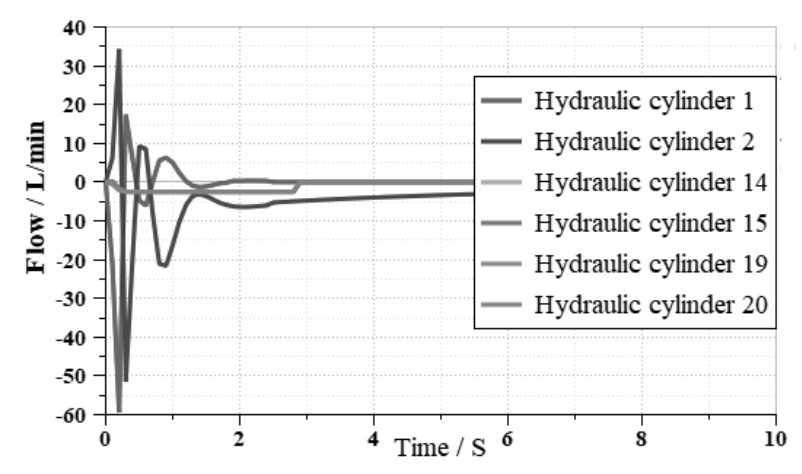

Fig. 6 Output flow curve of hydraulic cylinders 1, 2, 14, $15,19,20$

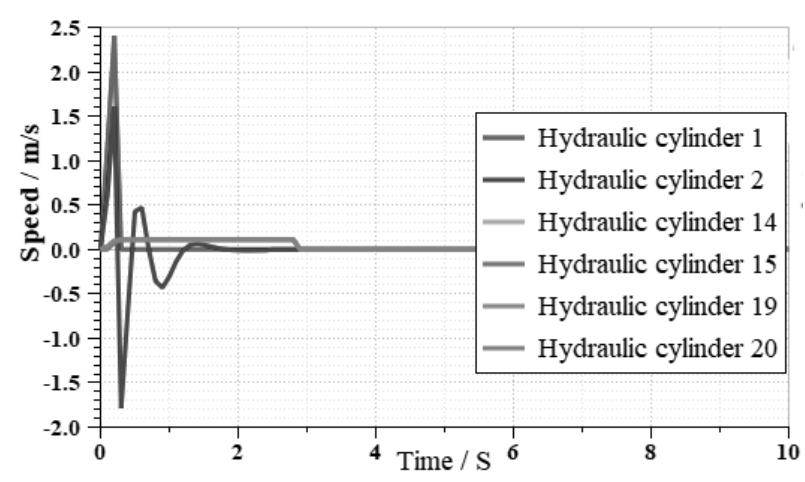

Fig. 7 Piston Speed Curves of Cylinders 1, 2, 14, 15, 19, 20

According to the simulation figures 4, 5, 6 and 7, the output displacement, output pressure, output flow rate and piston rod speed of the hydraulic cylinders $1,2,14$, 15,19 and 20 can be analysed macroscopically and stabilized after 2.5 or so. This is mainly due to loader hydraulic system start-up will produce a certain period of time fluctuations. From the microscopic point of view, the output pressure rises steadily from $0.2 \mathrm{~s}$ to $2.1 \mathrm{~s}$ when the displacement of the left steering cylinder 1 begins to stabilize after about $0.2 \mathrm{~s}$, and remains stable until $2.2 \mathrm{~s}$, while the output flow rate is in a state of flow quiescence after $2.5 \mathrm{~s}$. This is mainly because the job is already at rest at some point; and the piston speed is at rest at about 0.2 $\mathrm{s}$, the value is $0 \mathrm{~m} / \mathrm{s}$. Although from the above simulation 
results, the system has met the requirements of ZL50 loader, but with the national proposed energy conservation, emission reduction, and benefit maximization to analyze. We can also optimize the algorithm to study this, so as to maximize the benefit of construction machinery. At the same time, for this hydraulic system, it is only necessary to use this method to analyze a single hydraulic system. As such, that hydraulic system shown in FIG. 8 is propose separately for optimal analysis.

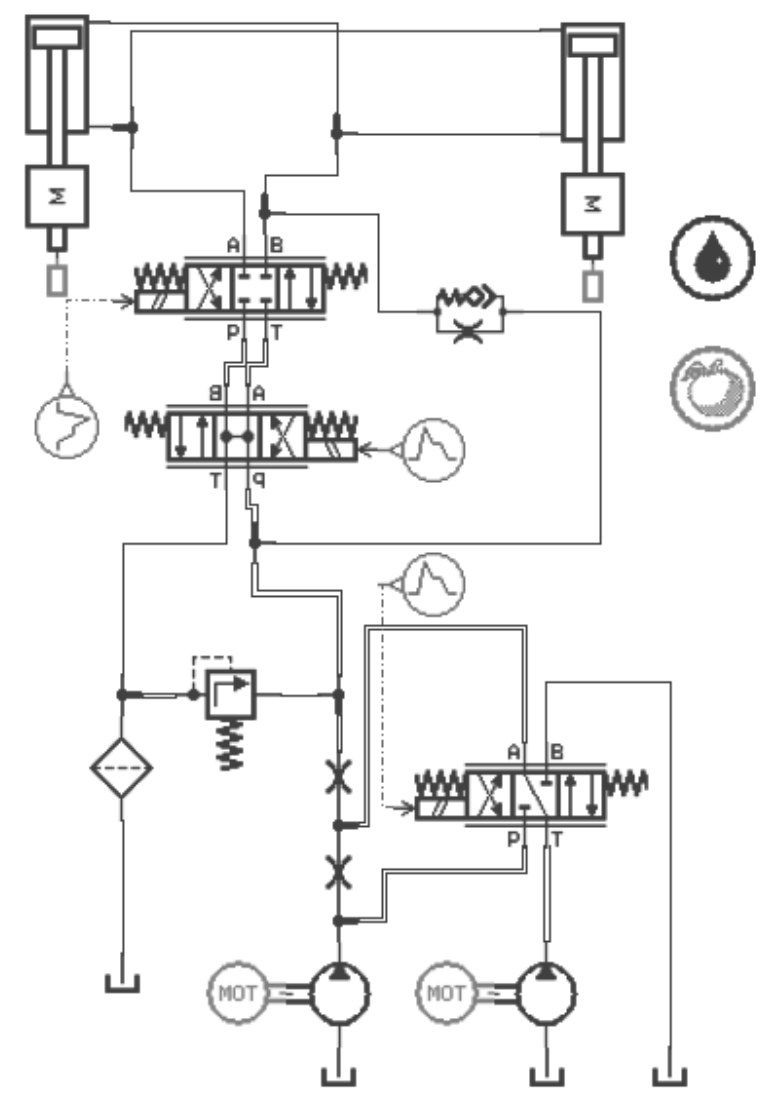

Fig. 8 Algorithm optimization of hydraulic system

\section{Analysis of Genetic Algorithm and Esta- blishment of Mathematical Model}

In view of the above analysis, this case uses genetic algorithm and neural network to compare the two algorithms, take the optimal value for simulation research.

\subsection{Theoretical analysis of algorithm}

A) Genetic Algorithm (GA) is based on parallel search of chromosome group, rotation operation with guessing property, exchange operation and mutation operation [13]. This particular combination distinguishes genetic algorithm from other search algorithms. A GA flowchart of that application of genetic algorithm to this feed component optimization is shown in figure 9.

As can be seen from figure 9, the multi-objective modelling of the loading and unloading system of the turret chuck is carried out at first, the variables corresponding to the objective functions are searched, a new set of GA data is obtained, and the generated data is corrected at the same time.

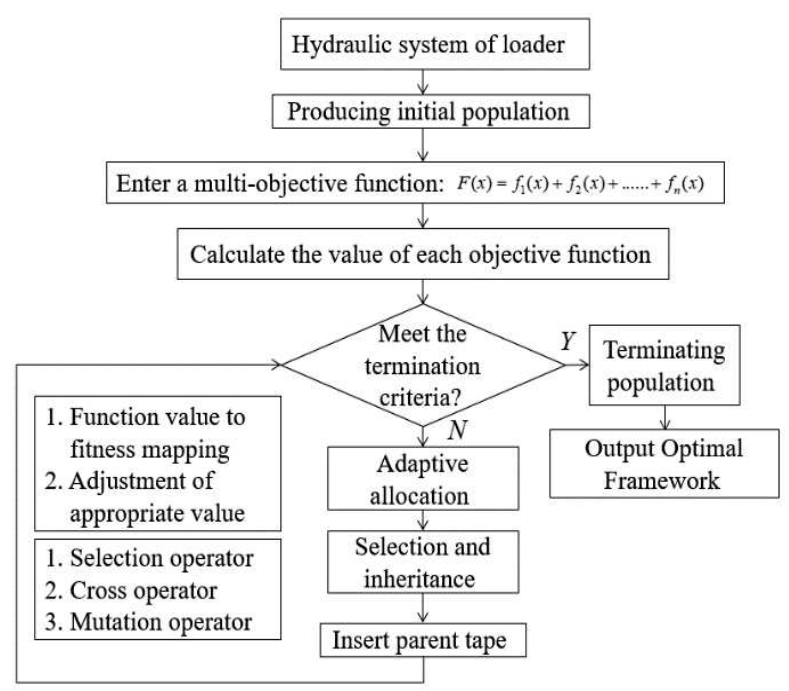

Fig.9 GA Algorithm Flowchart

B) BP (Back Propagation Network) neural network is a multi-layer feedforward neural network, which is composed of input layer, hidden layer and output layer [1415]. The input layer neuron receives the external input, the hidden layer and the output layer neuron process the signal, and the final result is output by the output layer neuron. The structure is shown in figure 10 .

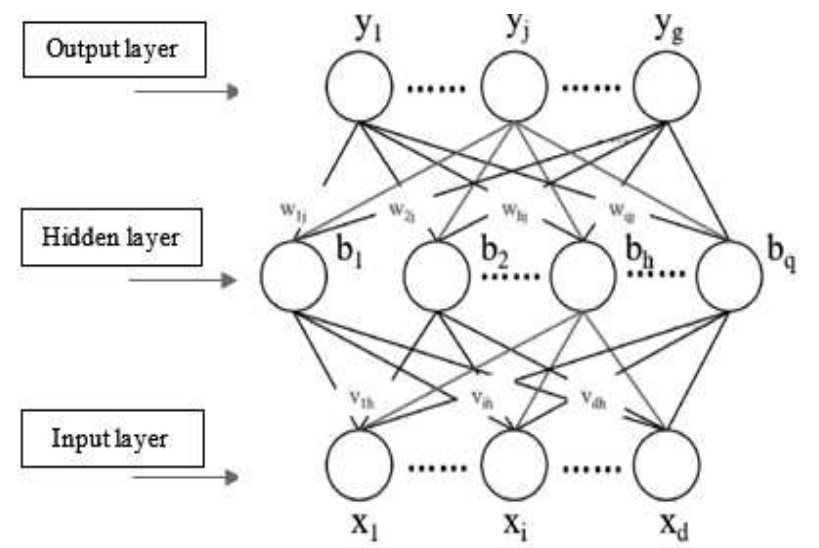

Fig. 10 BP Algorithm Structure Diagram

According to figure 10, the structure is a multi-layer feedforward network structure with $d$ input neurons, $g$ output neurons and $\mathrm{q}$ hidden layer neurons, in which the threshold of the $\mathrm{j}$-th neuron of the output layer is denoted by $\theta_{j}$ and the threshold of the h-th neuron of the hidden layer is denoted by $\gamma_{h}$. The connection weight between the i-th neuron of input layer and the h-th neuron of hidden layer is $v_{i h}$, and the connection weight between the $h$-th neuron of hidden layer and the $\mathrm{j}$-th neuron of output layer is $\omega_{h j}$. Note that the input received by the h-th neuron in the hidden layer is $\alpha_{h}=\sum_{h=1}^{d} v_{i h} x_{i}$, and the input received by the $\mathrm{j}$-th neuron in the output layer is $\beta_{j}=\sum_{h=1}^{q} \omega_{h j} b_{h}$, where $b_{h}$ is the output of the h-th neuron in the hidden layer. 


\subsection{Establishment of mathematical model of hydrau- lic system}

A Multi-objective Mathematical Model of Hydraulic System Optimization Frame.

According to the most important parameters in the hydraulic system of ZL50 loader, the mathematical model is established. Contains multi-objective functions, design variables, and constraint functions. According to the actual parameters of the system and working conditions, the optimal design of the hydraulic system of the loader can be expressed as:

$$
\left\{\begin{array}{l}
{\left[\begin{array}{l}
\min M=\sum_{i=1}^{n} F_{i}(m)=\left\{F_{1}(m)+F_{2}(m)+\cdots \cdots+F_{n}(m)\right\} \\
\max N=F(N)=\left\{F_{1}(N)+F_{2}(N)+\cdots \cdots+F_{n}(N)\right\} \\
N=\left(n_{1}, n_{2}, \cdots \cdots, n_{n}\right) \\
g_{n}(i)>0 ; i=A, B, P \\
A(N)>0 ; B(N)>0 ; P(N)>0 ;
\end{array}\right.}
\end{array}\right.
$$

Where: $A ; B ; P \quad$-design variable; $\min M$; $\max N$-objective function, $i=1,2, \ldots, \quad \mathrm{n}$; $A(N) ; B(N) ; P$-constraint function and equality constraint function; $A(N)>0 ; B(N)>0 ; \quad P>0$-the lower limit of the design variable;

B Optimized multi-objective function

In the optimization design of hydraulic system, all kinds of parameters change will affect the stability and construction efficiency of the hydraulic system. As a result, under the condition of satisfying the requirement of the hydraulic system of the ZL50 loader, the stability parameters of the hydraulic system can be transformed into the multi-objective that the average change value of each point is the minimum and the hydraulic transmission efficiency is the highest, which can be expressed as:

$$
\min M=\sum_{i=1}^{n} F_{i}(m)=\left\{F_{1}(m)+F_{2}(m)+\cdots \cdots+F_{n}(m)\right\}
$$

$\max N=F(N)=\left\{F_{1}(N)+F_{2}(N)+\cdots \cdots+F_{n}(N)\right\}$

Where $M$ is the total mass; $N$ is the total efficiency

\section{Constraint condition}

When setting constraints, we need to consider the rationality and difference of the parameters in the previous simulation analysis. Therefore, the displacement and rotational speed of the hydraulic pump $\mathrm{A}$ in the hydraulic system are represented by $A_{1}$ and $A_{2}$ respectively, and the displacement and rotational speed of the hydraulic pump B are represented by $B_{1}$ and $B_{2}$ respectively. The overflow valve opening pressure is expressed in $P$. Take these five parameters as design parameters and list the initial value, change range and the corresponding table of setting allocation parameter codes and design variables according to actual working conditions and experience, as shown in table 2.

After all the function expressions are normalized, the data in table 2 are brought into the model to obtain the multi-objective mathematical model for the optimal design of the hydraulic system, and the constraint conditi-

ons are satisfied at the same time: $\left\{\begin{array}{c}g_{1}(X) \geq 0 \\ g_{2}(X) \geq 0 \\ 80 \leq X_{1} \leq 130 \\ 850 \leq X_{2} \leq 1500 \\ 80 \leq X_{3} \leq 130 \\ 850 \leq X_{4} \leq 1500 \\ 110 \leq X_{5} \leq 210\end{array}\right.$

Tab. 2 Mapping Table of Hydraulic System Design Variables

\begin{tabular}{|c|c|c|c|}
\hline Design Variables & Parameter code & Initial value & Range of change \\
\hline$A_{1}$ & $X_{1}$ & 100 & $80-130$ \\
\hline$A_{2}$ & $X_{2}$ & 1000 & $850-1500$ \\
\hline$B_{1}$ & $X_{3}$ & 100 & $80-130$ \\
\hline$B_{2}$ & $X_{4}$ & 1000 & $850-1500$ \\
\hline$P$ & $X_{5}$ & 150 & $110-210$ \\
\hline
\end{tabular}

\subsection{Algorithm analysis result}

According to the optimization model of hydraulic system of ZL50 loader, combined with MATLAB software, genetic algorithm and neural network algorithm were used to optimize the hydraulic system, and the final comparison results were verified [10]. The corresponding values of the two optimization results are shown in Table 3.

Tab. 3 GA and Neural Network Algorithm Data Results

\begin{tabular}{|c|c|c|c|c|c|c|}
\hline Algorithm & \multicolumn{5}{|c|}{ value } & Number of iterations \\
\hline GA & 108 & 1200 & 108 & 1200 & 158 & 107 \\
\hline BP & 119 & 1194 & 119 & 1194 & 154 & 113 \\
\hline
\end{tabular}

\section{Comparative study}

Loading and simulating the optimized data results of the two algorithms in Table 3, two sets of data analysis and comparison graphs are obtained, as shown in figure 11, figure 12 , figure 13 , and figure 14 .
Figure 11 and figure 12, that GA parameter is simulated in the output pressure of the hydraulic cylinder 1 to be less than the "corner" of the original parameter, and the output pressure smoothness is better; Also in the hydraulic cylinder 1 output flow simulation curve, also reflects 
the characteristics of "corner" less. Figure 13 and figure 14: similar to that comparison between the GA parameter and the original parameters, there are less "turning point" and bet stability of the output pressure. The results show that the parameters optimized by GA or BP algorithm are better than the original parameters. However, from a macro perspective, GA and BP can be seen from figure 11, the simulation graphics contrast is more obvious, that is to say, the stability of the optimization results of GA parameters is higher than that of BP optimization parameters.

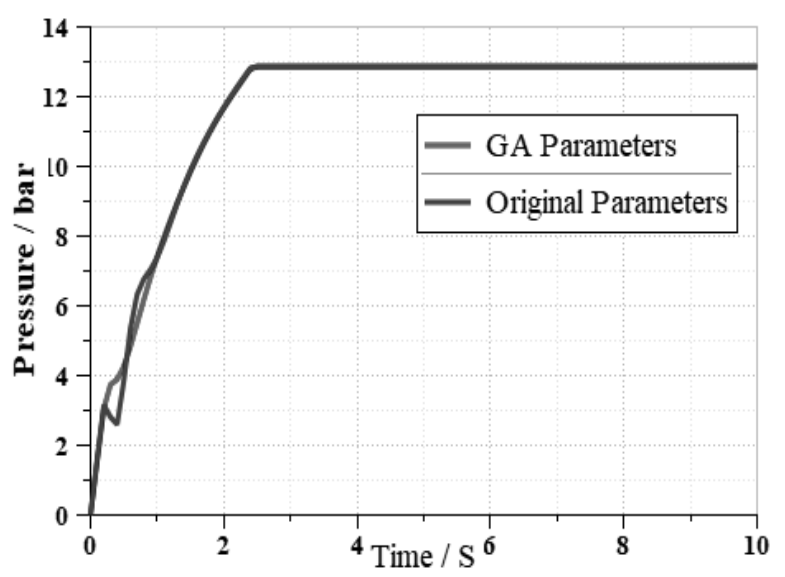

Fig.11 Hydraulic Cylinder 1 Output Pressure GA Comparison Diagram

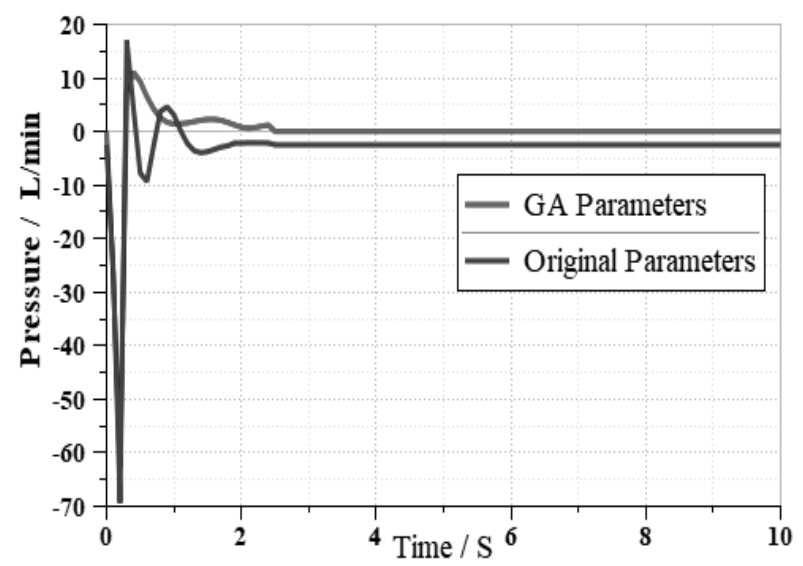

Fig.12 Hydraulic Cylinder 1 Output Flow GA Contrast Diagram

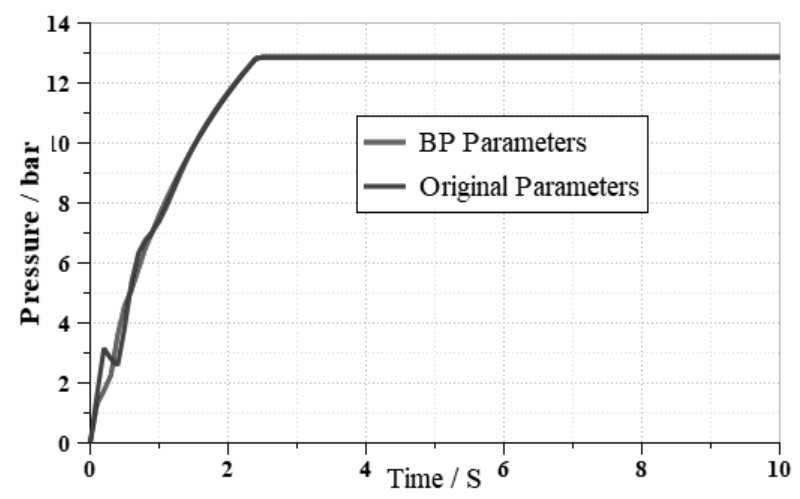

Fig.13 Output Pressure BP Comparison Diagram of Hydraulic Cylinder 1

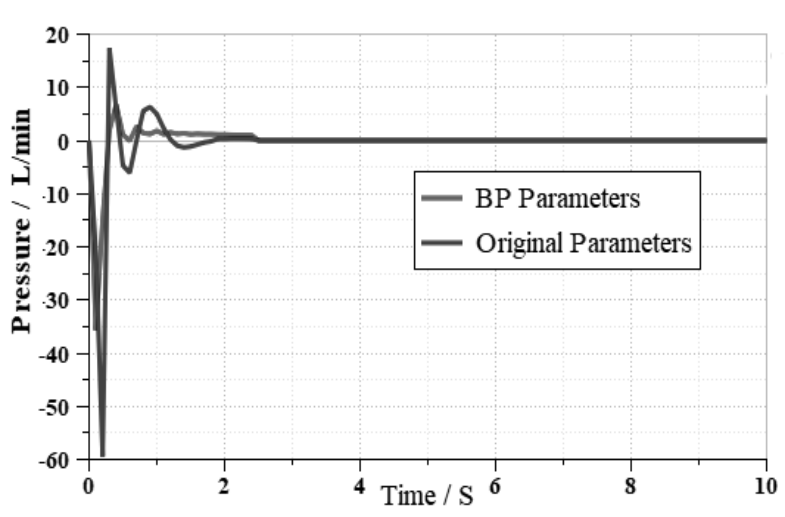

Fig.14 Output Pressure BP Comparison Diagram of Hydraulic Cylinder 1

\section{Conclusion}

(1) The hydraulic system of ZL50 loader is studied in this paper. Firstly, the research framework is established, and the schematic diagram of hydraulic system is designed, and the simulation analysis is carried out by using AMESim. At the same time, we get the correlation curve and put forward that we can use the optimization algorithm to optimize the hydraulic system parameters and compare and analyse.

(2) Then, GA and BP neural network algorithm are used to optimize and compare the parameters of hydraulic system. Secondly, the mathematical model of hydraulic system of ZL50 loader is established, and the two optimized parameters are substituted into the model and simulated by AMESim again, and the comparison curves between GA and BP are output. Through comparative analysis: for this case, the parameters optimized by GA and BP algorithm are better than the original parameters. Further analysis shows that the parameters optimized by GA algorithm are better than BP algorithm in stationarity. At the same time, this method is used to put forward research ideas and lay a theoretical foundation for similar studies.

\section{Acknowledgement}

This research is sponsored by The Chongqing Municipal Higher Education Teaching Reform Major Project in 2017 (171042) and The Industrial Robot Integration Chongqing Higher Vocational and Technical College Application Technology Promotion Center Project (Yu Jiao Ke Fa [2018] No.2)

\section{References}

[1] WAN YIPING, JIA JIE, SONG XUDING. (2017). Dynamics simulation and experimental study of loader working device [J]. Computer Simulation, 2017 (7)

[2] YOU YONG, SUN DONG-YE, LIU JUN-LONG. (2019). Automatic shift control strategy of hydraulic mechanical automatic transmission based on dynamic programming [J]. Journal of Mechanical Engineering, 2019, 55 (8): 106-117. 
[3] LIU FUXIN, DU DEJUN. (2007). Reasonable lubrication and centralized lubrication application of wheel loader [J]. Lubrication and Sealing, 2007, 32 (7): 154-155.

[4] JIAN Z. (2018). Working Principle and Energy Saving Analysis for Fixed/Variable Displacement Hydraulic System of Loader[J]. Chinese Hydraulics \& Pneumatics, 2018.

[5] PARK S H, ALAM K, JEONG Y M, et al. (2009). Modeling and simulation of hydraulic system for a wheel loader using AMESim[C]// Iccassice. IEEE, 2009.

[6] ZHOU YI, YU JIN (2008). Fluid transmission and control [M]. Beijing. Science Press. 2008.

[7] IVAN VOREL, ŠTĚPÁN JENÍČEK, JOSEF KÁŇA, VRATISLAV KOTĚŠOVEC. Optimization of Controlled Cooling of Forgings from Finishing Temperature with the Use of Light and Electron Microscopy [J]. Manufacturing Techno$\log y$.

[8] WEI Z D , DUN Z S Influences of friction condition and end shape of billet on convex at root of spline by rolling with round dies[J]. Manufacturing Technology.

[9] WANG, ZHUN. Research on the design of a millturn center [J]. Manufacturing Technology.
[10] WANG D, XIANPING W U, CHEN L, et al. (2005). Improvement of the Hydraulic Circuit of Two Parallel Speed Control Valves Controlling Two Work Speeds and Its PLC Control System[J]. China Metalforming Equipment \& Manufacturing Technology, 2005.

[11] SALLOOM M Y, SAMAD Z. (2011). Finite element modeling and simulation of proposed design magneto-rheological valve[J]. International Journal of Advanced Manufacturing Technology, 2011, 54(5-8):421-429.

[12] LIANG L, WEI D, WANG X, et al. (2016). Effects of hydraulic pressure on wrinkling and earing in micro hydro deep drawing of SUS304 circular cups[J]. International Journal of Advanced Manufacturing Technology, 2016:1-9.

[13] MORRIS G M, GOODSELL D S, HALLIDAY R $\mathrm{S}$, et al. (2015). Automated docking using a Lamarckian genetic algorithm and an empirical binding free energy function[J]. Journal of Computational Chemistry, 2015, 19(14):1639-1662.

[14] BEYER H G. (1999). The simple genetic algorithm:foundations and theory[M]. 1999.

[15] TANG L, YUAN S, TANG Y, et al. (2019). Optimization of impulse water turbine based on GABP neural network arithmetic[J]. Journal of Mechanical Science and Technology, 2019, 33(1):241-253. 